\title{
A PENHORA JUDICIAL DE MOEDA VIRTUAL
}

Adriana Baker Goveia Araujo, Nyeda Yuri Santos Kiyota Dan

Universidade do Oeste Paulista-UNOESTE - DIREITO, Presidente Prudente, SP. E-mail:adrianabgaraujo@gmail.com, nyedakiyota@hotmail.com

\begin{abstract}
RESUMO
É sabido que a tecnologia tem inovado diariamente o cotidiano da sociedade, a começar da transformação de simples aplicativos de aparelhos móveis até sua amplitude ao auferir a medicina e o judiciário. Não olvidando sua ingerência mais coeva, qual seja, a moeda virtual, a qual compreende especialmente o mundo financeiro e o meio forense. Desta feita, com tantas alterações ocorrendo na vida diária dos indivíduos é imprescindível que o ordenamento jurídico acompanhe este progresso tecnológico. Portanto, este estudo pretende abarcar a possibilidade de a penhora judicial recair sobre a moeda virtual durante a execução, realizando uma correlação entre o direito e a rede mundial de computadores. Assim sendo, este artigo foi embasado em levantamentos bibliográficos, leituras de leis e artigos eletrônicos, onde os elementos informativos foram examinados com a aplicação do método hipotético dedutivo.
\end{abstract}

Palavras-chave: moeda virtual; internet; execução; penhora.

\section{THE JUDICIAL COURT OF VIRTUAL CURRENCY}

\begin{abstract}
It is well known that technology has daily innovated the daily life of society, starting from the transformation of simple applications of mobile devices to their amplitude when gaining medicine and the judiciary. Not forgetting his most common intervention, that is, the virtual currency, which especially understands the financial world and the forensic environment. This time, with so many changes occurring in the daily lives of individuals, it is imperative that the legal system accompany this technological progress. Therefore, this study intends to cover the possibility of judicial attachment to the virtual currency during the execution, making a correlation between the right and the world wide computer network. Thus, this article was based on bibliographical surveys, readings of laws and electronic articles, where the informative elements were examined with the application of the hypothetical deductive method.
\end{abstract}

Keywords: virtual currency; Internet; execution; garnishment. 


\section{INTRODUÇÃO}

A evolução da sociedade desde os primórdios da humanidade adveio principalmente em virtude do desenvolvimento do raciocínio lógico de cada indivíduo. Logo, é inegável que a inteligência do ser humano produziu ideias extraordinárias que se concretizaram em projetos, como automóveis, aparelhos médicos, construções e a rede mundial de computadores.

Deste modo, a vida diária de qualquer pessoa está repleta de inovações, desde o despertar até o seu repouso após um longo dia de trabalho; sendo manifesto que em decorrência desta habitual evolução tecnológica surge uma nova temática para a sociedade, qual seja, a moeda virtual.

Portanto, o objetivo deste artigo científico é averiguar uma entre inúmeras possibilidades de aplicação desta inovadora cédula digital, isto é, a viabilidade da penhora judicial incidir sobre a moeda virtual na execução civil.

\section{METODOLOGIA}

O presente trabalho será desenvolvido por meio de bibliografias, legislações e artigos eletrônicos, onde se efetivará um estudo pelo método hipotético-dedutivo e contenda dialética. Sobrevindo uma averiguação no ordenamento jurídico brasileiro sobre a possibilidade da incidência da temática abordada, bem como uma explanação sobre os aspectos relevantes da moeda virtual e da penhora na execução civil.

\section{RESULTADOS}

Após a realização de um estudo sobre a temática abordada, o qual envolveu o ordenamento jurídico e a rede mundial de computadores, remanesceu axiomática a dificuldade de concretização da penhora na execução civil recair sobre a moeda virtual; em virtude da dificuldade de localização de seu proprietário, pois determinadas informações são protegidas por criptografia, ou seja, uma forma de enlear as informações com a finalidade de manter os dados seguros e ocultos, facilitando desta forma transações ilícitas.

\section{DISCUSSÃO}

O processo de execução na esfera civil entende-se como uma atividade jurisdicional que visa à satisfação de um direito previamente constituído, isto é, busca-se a efetivação, promoção factual daquele.

A execução invariavelmente deve ser instrumentalizada, quer dizer, se subordina a existência de um título representativo da obrigação. Tal documento concebe-se de forma judicial ou extrajudicial. O primeiro advém de uma ação de conhecimento, nela desenrola-se todo procedimento cognitivo de formação de convencimento do julgador, que quando findo resulta em uma sentença constitutiva do direito pleiteado consubstanciado no título executivo. Enquanto que no extrajudicial o credor já é detentor desse documento, foi "produzido fora do processo jurisdicional, ao qual a lei atribuiu eficácia executiva" (GONÇALVES, 2017, p.27). Como a nomenclatura insinua, o titular do direito o possui sem a exigência de movimentação da máquina judiciária para criá-lo e legitima-lo, conserva em si mesmo a aptidão para ser executado.

Impende salientar que a Lei no 11.232 de 22 de dezembro de 2005 trouxe profundas modificações no processo executório. Antes de sua vigência o CPC 1973 tratava a execução de título judicial em um processo autônomo, havia duas tramitações processuais distintas e sucessivas. A nova estruturação ocasionou um processo sincrético, único, contendo em seu bojo atividades cognitivas e satisfativas, com isso a execução faz-se na mesma relação processual, onde o Estado-juiz "se põe a praticar atos de outra qualidade (SCARPINELLA, 2013, p.71)", com fito de perfazer o direito precedentemente validado por ele. Cuida de uma nova fase processual ante o inadimplemento da prestação pelo executado, de modo que a satisfação se dará por intermédio 
da invasão de seu patrimônio de quantos bens bastem para que, à custa dele alcance-se o direito material. Assim qualquer que seja a execução haverá constrangimento estatal sobre o patrimônio, que procederá a uma apreensão forçada com vistas à satisfação do exequente (ASSIS, 1987).

O CPC comtempla quatros espécies de execução que variam acordo com a natureza da obrigação devida, adequam-se, portanto ao direito versado. Assim será: de fazer; não fazer; de entrega de coisa certa e por quantia certa. Tendo em vista a temática proposta neste trabalho, importa-nos tratar apenas da execução por quantia certa, regulada nos artigos 824 e seguintes de CPC.

É admissível frente à negativa de pagamento de quantia precisa em dinheiro pelo devedor ao credor. Perante tal recusa o Estado opera a expropriação dos bens daquele, todavia é imperativo que se aponte quais, dado que alguns não são passiveis de execução, e quantos serão despojados do patrimônio total, tal ato é denominado penhora. Destarte, conclui-se tratar de um procedimento instrumental, preliminar, no magistério de Marcelo Abelha (2015, p. 395) "torna concreta a responsabilidade executiva, na medida em que individualiza o(s) bem(ns) que será(ão) expropriado(s)", assumindo um papel de pô-los a salvo "para que seja exitoso o ato final de expropriação (ABELHA, 2015, p. 396)".

Estes estão elencados gradativamente no art. 835 CPC, que fixou um arranjo sequencial, cujo parâmetro adotado foi a maior incomplexidade de converter o bem em dinheiro, sucedendo uma execução célere e profícua, bem como menor onerosidade para o executado. Conquanto, tal ordem não é absoluta, defronte a algumas circunstâncias é factível que sobrevenha inversão.

Prioritariamente recairá sobre dinheiro, por ser o intento central da execução. Contudo, é costumaz deparar-se com ausência deste quando inquirido, neste contexto proceder-se-á a tomada de outros bens. Importa-nos estudo do previsto no inciso III do aludido artigo, qual se a penhora de títulos e valores mobiliários com cotação no mercado. Sinteticamente são documentos emitidos em escala substancial por empresas com propósito de angariar recursos para seu financiamento, corresponde para aqueles que as adquirem um investimento (ULHOA, 2010). O art. 20 da Lei $n=6.385 / 76$ traz um rol exemplificativo do que é tido como valores mobiliários, entre eles acham-se as ações.

Ações são unidades que correspondem a uma parcela do capital social da sociedade anônima que as emite, e "atribui ao seu titular a condição de sócio desta" (ULHOA, 2010, p. 101). Sendo um valor mobiliário para que uma aludida sociedade possa ofertar suas ações na Bolsa de Valores é impreterível que tenha inscrição na Comissão de Valores Mobiliários (CVM), cuja função precípua é regulamentar, fiscalizar e autorizar o andamento do mercado de valores. É dela a responsabilidade de proteção aos investidores em geral, nas transações comerciais, sendo ainda autorizada a competência para aplicar sanções, consoante ao art.11 da supradita lei.

Isto posto, uma conjectura deve ser considerada na época coeva, isto é, a penhora recair sobre a moeda virtual; a qual é considerada dinheiro na rede mundial de computadores. Porém, a diferença reside no fato de que este é um dinheiro digital que não pode existir no mundo físico, somente na internet.

Portanto, é evidente que este tipo de moeda surgiu em decorrência da evolução do dinheiro e da tecnologia, não olvidando as crises financeiras que permeiam a sociedade em determinados períodos. Logo, se faz necessário um exame de seus principais aspectos.

O seu mecanismo básico de transação é que ela é trocada de um computador para outro por meio da rede (internet), sem a interferência de qualquer instituição financeira ou governo. Existem vários tipos de moedas virtuais: bitcoin, litecoin, peercoin, entre outras; bem como há diversas moedas físicas atualmente em circulação, como o euro, o dólar, o real, o franco, o peso, e assim por diante; tendo estas como diferencial que são emitidas e controladas pelo Estado e não por um complexo algoritmo de computador. 
Importante ressaltar que cada moeda possui uma forma de funcionamento díspar. Mas de uma forma geral, "as operações com moedas virtuais são feitas em carteiras virtuais, que funcionam como uma espécie de endereço de e-mail: é possível enviar e receber quantias por meio delas. A verificação da validade de uma transação é feita por complexos sistemas de criptografia que demandam computadores com grande capacidade de processamento (RACON, 2018)".

Uma das moedas mais famosas e utilizadas é o bitcoin, sendo este "basicamente um arquivo digital que existe online e funciona como uma moeda alternativa. Ele não é impresso por governos ou bancos tradicionais, mas criado por um processo computacional complexo conhecido como "mining" (mineração). Todas as moedas e todas as transações feitas com elas ficam registradas em um índice global conhecido como blockchain, uma espécie de banco de dados descentralizado que usa criptografia para registrar as transações. Dessa forma, os arquivos não podem ser copiados ou fraudados e as transações não podem ser rastreadas (UOL ECONOMIA, 2017)".

Data vênia, a Receita Federal já se posicionou no sentido da declaração de moedas virtuais no imposto de renda, in verbis: "Todos os bens o contribuinte precisa declarar, inclusive essas moedas virtuais, informou o supervisor nacional do IR do Fisco, Joaquim Adir (G1 ECONOMIA, 2018)".

É evidente que a medida visa combater a lavagem de dinheiro no Brasil, (Lei no 9.613/98), elisão e evasão fiscal (Lei 5.172/66) (SANTOS, 2018). Logo, é irrefutável que o Estado tenta controlar tais numerários dos contribuintes, porém, olvida que se o indivíduo optar por não declará-las não existe medidas específicas a serem adotadas.

Importante ressaltar a existência do projeto de Lei no 2303/2015 no Brasil, o qual incide na regulamentação sobre o referido tema, porém, até o momento, este possui um futuro incerto no ordenamento jurídico, buscando a inclusão das moedas virtuais nos programas de milhagem aéreas na definição de arranjos de pagamento sob a supervisão do Banco Central. Já a Comissão de Valores Mobiliários (CVM), autarquia responsável por regulamentar e fiscalizar a atividade no mercado de valores publicou um ofício proibindo administradores e gestores de fundos no Brasil de investirem em criptomoedas. O órgão alegou que as discussões sobre a legalidade e segurança das criptomoedas no país ainda não está definida, inclusive não deixou de citar a recente situação criada pelo Projeto de Lei no 2303/2015, o qual tem abarcado a possibilidade de criminalizar esse tipo de investimento, sendo contrário ao texto de lei inicialmente sugerido (YAMAMOTO, 2018).

Nada obstante, os artigos 21, inciso VII; e 164 ambos da Constituição Federal, discorrem que somente a União por meio do Banco Central do Brasil (BACEN) possui a competência para emitir moedas, in verbis:

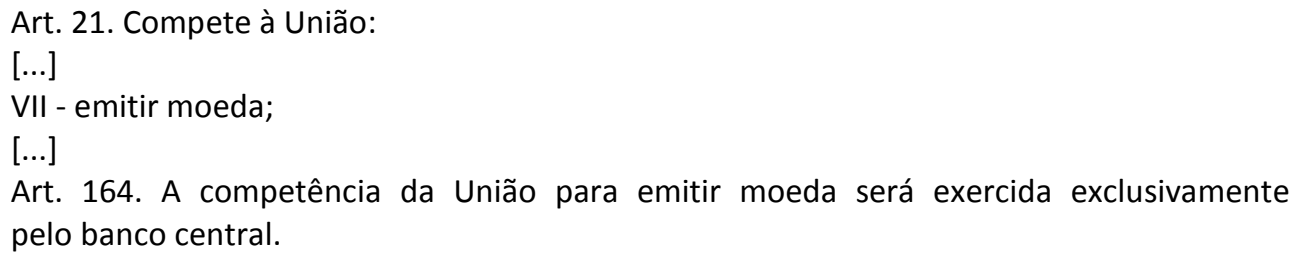

Conquanto, o principal obstáculo para que a penhora judicial recaia sobre qualquer tipo de moeda virtual é a dificuldade de rastrear e evidenciar o proprietário.

Para abrir uma conta bancária convencional, por exemplo, são necessários vários documentos, como uma identificação válida e uma prova de residência, ao passo que, para se registrar em um sistema que transaciona por meio de moedas digitais, basta um endereço IP válido. No entanto, existem várias técnicas para ocultar o endereço IP real, como o uso de proxies, o que dificulta o rastreamento de usuários maliciosos. O processo de rastreamento dos fluxos de 
caixa na modalidade criptografada se torna difícil e mais confusa devido aos seguintes fatores: falta de comunicação entre as pessoas do ambiente real e contas de moeda virtual; existência de obstáculos para rastreamento, como misturadores de criptografia e anonimizadores; possibilidades de criação de um número ilimitado de contas e falta de regulamentação (ANDRADE, 2017).

Neste sentido o Tribunal de Justiça de São Paulo:

AGRAVO DE INSTRUMENTO. Execução de título extrajudicial. Penhora de moeda virtual (bitcoin). Indeferimento. Pedido genérico. Ausência de indícios de que os executados sejam titulares de bens dessa natureza. Decisão mantida. Recurso desprovido.

(TJ-SP 22021573520178260000 SP 2202157-35.2017.8.26.0000, Relator: Milton Carvalho, Data de Julgamento: 21/11/2017, 36a Câmara de Direito Privado, Data de Publicação: 21/11/2017)

Porém, a professora de Direito Empresarial da UFF, Márcia DalCastel, explica que Bitcoin é um bem como qualquer outro e não há qualquer impossibilidade na sua penhora. "Na prática, segue a regra de qualquer execução. Encontrado o bem, requer-se a penhora" (ANTUNES, 2018).

\section{CONCLUSÃO}

Data vênia, conclusa perfaz esta pesquisa de que a tecnologia deve estar atrelada com o mundo jurídico, pois as diversas relações entre os indivíduos no período atual incidem de forma física e virtual.

Portanto, apesar de vários estudos serem realizados constantemente sobre a temática abordada, é fatídico concluir que na época coeva a penhora de moeda virtual na execução civil encontra obstáculos que futuramente devem ser transponíveis, principalmente pela elaboração de Leis que regulem o referido tema, tornando inócuo o anacronismo legislativo e jurídico que impera na atualidade.

\section{REFERÊNCIAS}

ABELHA, Marcelo. Manual de execução civil. 5 ed. Rio de Janeiro: Forense, 2015.

ANDRADE, Mariana Dionísio de. Tratamento jurídico das criptomoedas: a dinâmica dos bitcoins e o crime de lavagem de dinheiro. Revista brasileira de políticas públicas. Disponível em: <https://www.publicacoesacademicas.uniceub.br/RBPP/article/viewFile/4897/3645>. Acesso em 09 de agosto de 2018.

ANTUNES, Alexandre. Judiciário já vê chance de penhora de bitcoin no Brasil. Portal do Bitcoin. Disponível em: < https://portaldobitcoin.com/judiciario-brasileiro-penhora-de-bitcoin/>. Acesso em 09 de agosto de 2018

ASSIS, Araken de. Manual do processo de execução, v. 1, p. 22. Porto alegre: Legur, 1987.

BRASIL. Código de Processo Civil. Lei no 13.105, de 16 de março de 2015. Disponível em: <http://www.planalto.gov.br/ccivll_03/_Ato2015-2018/2015/Lei/L13105.htm>. Acesso em 15 de agosto de 2018.

BRASIL. Constituição (1988). Constituição da República Federativa do Brasil. Brasília: Senado Federal, 1988. 
BRASIL.Lei $\mathrm{n}^{\circ}$ 5.172, de 25 de outubro de 1966. Diário Oficial da União, Brasília, DF, 25 out. 1966. Disponível em: <http://www.planalto.gov.br/ccivil_03/LEIS/L5172.htm>. Acesso em 15 de agosto de 2018.

BRASIL.Lei $n^{\circ}$ 6.385, de 7 de dezembro de 1976. Promulgada em 07 de dezembro de 1976. Diário Oficial da União, Brasília, DF, 07 dez. 1976. Disponível em: <http://www.planalto.gov.br/ccivil_03/LEIS/L6385.htm>. Acesso em 15 de agosto de 2018.

BRASIL. Lei no 9.613, de 03 de março de 1998. Diário Oficial da União, Brasília, DF, 03 mar. 1998. Disponível em: <http://www.planalto.gov.br/cclVIL_03/leis/L9613.htm>. Acesso em 15 de agosto de 2018.

BRASIL. Lei $n=11.232$, de 22 de dezembro de 2005. Altera a Lei $n^{\circ} 5.869$, de 11 de janeiro de 1973 - Código de Processo Civil. Diário Oficial da União, Brasília, DF, 22 dez. 2015. Disponível em: <http://www.planalto.gov.br/ccivil_03/_ato2004-2006/2005/lei/l11232.htm>. Acesso em 15 de agosto de 2018.

BUENO, Cassio Scarpinella. Curso sistematizado de direito processual civil : tutela jurisdicional executiva, v. 3, 7 ed. São Paulo: Saraiva, 2013. Pg 71.

COELHO, Fábio Ulhoa. Curso de direito comercial: sociedades, v.2, 14 ed. São Paulo: Saraiva, 2010.

G1 Economia, Imposto de Renda 2018: veja como declarar posse e lucro com bitcoin e outras moedas virtuais. Disponível em: <https://g1.globo.com/economia/imposto-derenda/2018/noticia/imposto-de-renda-2018-veja-como-declarar-posse-e-lucro-com-bitcoin-eoutras-moedas-virtuais.ghtml>. Acesso em 09 de agosto de 2018.

GONÇALVES, Marcus Rios. Novo curso de direito processual civil, v 3, 10 ed. São Paulo: Saraiva, 2017.

PL 2303/2015, de 22 de dezembro de 2005. Projeto de Lei que dispõe sobre a inclusão das moedas virtuais e programas de milhagem aéreas na definição de "arranjos de pagamento" sob a supervisão do Banco Central. Disponível em: <https://www.camara.gov.br/proposicoesWeb/fichadetramitacao?idProposicao=1555470\#marcac ao-conteudo-portal>. Acesso em 15 de agosto de 2018.

RACON BLOG, Moedas Virtuais: como funcionam e como tirar proveito delas. Disponível em: <https://blog.racon.com.br/planejamento-financeiro/moedas-virtuais-como-funcionam-e-comotirar-proveito-delas/>. Acesso em 09 de outubro de 2018.

SANTOS,Valter dos. Jusbrasil, Criptomoedas - Área do direito que certamente você irá atuar! Disponível em: <https://santosvalter.jusbrasil.com.br/artigos/604128026/criptomoedas-area-dodireito-que-certamente-voce-ira-atuar>. Acesso em 09 de agosto de 2018.

UOL ECONOMIA, Bitcoin, o que é e como funciona a moeda virtual. Disponível em: $<$ https://economia.uol.com.br/noticias/bbc/2017/12/11/bitcoin-o-que-e-e-como-funciona-amoeda-virtual.htm>. Acesso em 09 de outubro de 2018.

YAMAMOTO, Maria Cecilia. Jusbrasil - Criptomoedas: elas são o futuro. A regulamentação no Brasil segue na contramão do mundo. Disponível em: 
<https://ceciliyamamoto.jusbrasil.com.br/artigos/536455405/criptomoedas-elas-sao-o-futuro>. Acesso em 09 de agosto de 2018. 